\title{
Dialectics of Natural-Artificial in the System of Language
}

\author{
Mariia A. Abysova ${ }^{1, *}$ \\ Olha P. Antipova ${ }^{2}$ \\ Bohdan V. Kalynovskyi ${ }^{3}$ \\ Myroslav Yu. Durdynets ${ }^{4}$ \\ Yurii P. Prykhodko5 \\ ${ }^{1}$ PhD, Department of Philosophy, National Aviation University, Kyiv, Ukraine \\ ${ }^{2} \mathrm{PhD}$, Department of the Preparation of Educational and Scientific Literature, \\ National Academy of Internal Affairs, Kyiv, Ukraine \\ ${ }^{3}$ Doctor, Department of Constitutional Law and Human Rights, \\ National Academy of Internal Affairs, Kyiv, Ukraine \\ ${ }^{4} \mathrm{PhD}$, Department of Philosophy of Law and Legal Logic, \\ National Academy of Internal Affairs, Kyiv, Ukraine \\ ${ }^{5} \mathrm{PhD}$, Department of Forensic Support and Forensics, \\ Educational and Scientific Institute No. 2, \\ National Academy of Internal Affairs, Kyiv, Ukraine \\ *Corresponding Author
}

Doi: 10.36941/ajis-2020-0024

\section{Abstract}

The article examines the problem of the dialectic nature of the language system. The analysis of a number of works on the philosophy of language has shaped research logic of authors, which guided the definition of the concepts of "natural language" and "artificial language". It is shown that the "natural - artificial" dichotomy in a language system is revealed through the prism of a number of paired constructs: "natural - social", "oral-written"; "folk-literary"; "informal-etiquette-formal”; "objective-subjective"; "autochthonous borrowed"; "traditional - innovative". The different genesis of the natural and artificial languages proves that the artificial languages are aimed at the intended result, while the natural can be considered as a side effect of communicative-linguistic activity, which is not provided by its purposes.

Keywords: natural, artificial, dialectic, language, system

\section{Introduction}

The problem of the correlation of natural and artificial raised in the Antiquity for the first time is one of the most important in the history of the philosophical thought. The categories "natural - artificial" point out to the ontological characteristics of the objects of internal and outside reality, according to which they differ in the way of origin, existence and disappearance. The definition of artificial and natural presented by Aristotle (2014): 'Among the existing objects, some exist by nature, and others - 
for other reasons" - has become classical. Unlike the natural things that exist and have the inner source of motion and rest by nature, the things known as artificial ones exist because of other reasons, having no innate principle of change.

The "natural - artificial" dichotomy is necessary for a man to find what is determined by the spontaneous development of nature, being formed by itself, without conscious human participation and intervention, and what comes from man himself, from his work, invented and embodied with some purpose.

The key to understanding of the "natural - artificial" ratio can be the language as a result of the interaction of two different mechanisms: artificial, purposefully regulated, consciously used according to the norms and expressed in teleological terms; and a natural mechanism, which is described in terms of objectified phenomena, spontaneous processes, environment conditions, and is fixed by means of models, laws and regularities. The distinction between natural and artificial in the linguistic field is relevant in the theoretical context to the study of communicative and epistemological properties of languages aimed at the usage for applied purposes, such as: a programming language; a symbolic record of scientific facts in mathematics, physics, chemistry; an international means of communication; a means of communication with the extraterrestrial mind; an artificial intelligence language system, etc.

\section{Materials and Methods}

The systemic review of literature allowed us to determine the logical sequence of the process of scientific research: to find out the essence of the concept of "natural language", the genesis of the formation of language layers, the interconnection of natural and artificial as the key principles of the language as a system in the context of dichotomy of "natural-social", "objective-subjective", "traditional - new", etc.; determine the criteria of the division of the classes of natural and artificial languages. The methodological basis of the study is a socio-cultural approach that makes it possible to comprehend the linguistic phenomena as a complex system, which is formed through the prism of the cultural component of the life of society.

\section{Theory}

The ambivalence of the phenomenon of "natural - artificial" is particularly activated in the context of modern socio-cultural space, in which the language, undergoing significant changes, turns to be a phenomenon capable of spontaneously and purposefully reflecting the 'new, post-human status of man in the world' (Kutyrev, 1994). It is quite logical that modern scholars, comparing these two realities, two contradictory worlds, often state the dominant influence of artificial, the growth of the possibilities of its autonomous functioning in comparison with the natural, its immense potential in relation to the representation of reality (Kutyrev, 1994), especially in the context of artificial intelligence, trying to give moral and emotional component to it (Kamal, 2018; Kirk, Nyga \& Beetz, 2014; Sova, 2014). At the same time, scholars emphasize the universality of the phenomenon of natural, in particular, the natural language as a "complex of absolute universals" (Moskovsky \& Libert, 2006), as a "naturalness natural", as a meta-language, a means of "universal language of international communication" (Smokotin, Petrova \& Gural, 2017), deliberately interpreted as a "universal semiotic matrix, where it is possible to build a virtually unlimited number of different sign or informational systems' (Panov, 2017). Natural language is used to form new concepts (settings, norms of behavior) that determine the way of human thinking, and therefore, the process of perception and reproduction of reality. The modern information space in general is known to be a rule-making structure, which prompts the formulation of certain norms, as well as streamlining of the situation within its implementation (Tselishcheva, 2016). These characteristics indicate the interdependence of the categories of "natural" and "artificial" and their dialectical relationship, which is clearly traceable in the language system. 


\section{Results and Discussion}

\subsection{Results}

On the basis of linguo-philosophical researches, the issue of dialectics of "natural - artificial" nature in the system of language is analyzed. A brief excursion into the history of linguistic studies proved the ratio of natural and artificial in the language is presented through the prism of a number of paired constructs: "natural - social”, "oral - written"; "folk - literary"; "informal - etiquette-formal"; "objective - subjective"; "autochthonous - borrowed"; "traditional -innovative".

The language as a holistic complex system is revealed as a result of the interaction of two mechanisms: artificial - regulated by goals, consciously used norms, expressed in teleological terms, and natural - shaped by spontaneous processes and authorized by traditions.

\subsection{The essence of the concept of "natural language"}

In the proper sense of the word, the human language as the most important means of communication and expression of thought is called "natural language". But does the word "natural" in this case mean "the one given by nature"? The language of animals, of course, can be considered "natural", since their communicative activity requires certain physiological support. For instance, in beeswax communication, one of the means of communication governing the behaviour of bees is the release and distribution of a special uterus substance by a queen bee. Being communicatively meaningful (that is, being a message), the release of the uterus is biologically significant, as it is a necessary link in biological cycle of a swarm.

In biological semiotics, there are no signs of different levels: simple and complex (composed of simple). Thus, according to zoopsychology, in the languages of troops of monkeys, there are about 30 sound signals that correspond to 30 standard situations, but all the signs are not decomposable into meaningful components. In terms of linguistics, one can say that in a communication of animals a separate message is simultaneously a "word" and a "sentence", that is, a message is not divided into meaningful constituents; it is indivisible. The one-level structure of biological semiotics limits their content to a set of output values, since complex signs (comprised of simple ones) are impossible.

There is no innate language among the several thousand languages of peoples known on the globe. The same object in different languages is designated by different aural symbols. Such a state of affairs would have been impossible if the nature of things allowed only one, "correct" name. There is no naturally necessary connection between sound and meaning in human language, but there is only a socially necessary connection, due to the tradition and the need for mutual understanding within the group speaking this language.

The ability to combine words in different ways provides people with inexhaustible resources for expressing new meanings. All of them were "treated" by a collective bearer of language for millennia and are re-assimilated and "cherished" by each speaker. Arbib (2012) associated the ability to create different languages with such a feature as multimodality, which allows the scholar to suggest a hypothesis about a kind of "mirror system of the brain", which enables perception, recognition and reproduction of a series of actions, and thus contributes to the formation of the speech in general, as well as numerous combinations of elements of a sign system in particular. The diversity of the human language as a result of the unmotivatedness of the form of a sign in relation to its content is confirmed by the connection of the origin of the human language with collective experience and consciousness, separating it by the chasm from the language of animals. So, if the language of animals is formed on the basis of a certain 'innate information that allows them to live among other similar individuals' (Lorenz, 2016), a person receives, in addition to innate information, the opportunity to learn how to communicate with other people, that is, the ability to produce information, to coordinate his/her own individual experience with the experience of other people (Panov, 2017). According to Corballis (2017), before speech appeared people were driven by the desire to share their 
thoughts, because thinking appeared long before the language. Thanks to language man, unlike an animal, gained, at a certain stage of development, the ability to reflect past, describe present and predict future.

Human language is the objectivization of the leap out of the unconsciously biological to the consciously social being. The fact that the language in the ontogenetic and in the phylogenetic dimension is born on the social not on the biological basis enables one to relate the language of an animal and the language of man. Consequently, the notion of "natural language" refers to fuzzy concepts, whose definitions are based mainly on habits. Among traditional approaches to the interpretation of the concept of "natural language", there is a point of view expressed by Baudouin de Courtenay (2018), that folk language in its opposition to literary language is identified with "natural": '... the obvious need to emphasize the difference between languages in the natural state and artificially developed, literary languages - a difference which can find an analogue among the wild and domestic animals, wild and cultivated plants".

In its historical development, language moves from chaos to plan. Languages of tribes and nationalities are mostly oral, and even those which have their own writing system(s) are not standardized; they lack or almost lack written literature. Since they precede the formation of national normalized languages, they are sometimes called pre-national, folk. In contrast to them, national languages, characterized by literary norms, combine early chaos (naturalness) and late codification (artificiality). Languages that are unregulated in the changing variety of their dialects and subdialects and the normalized languages (the first ones are oral, the latter - written, literary, national) are two stages in the linguistic development of society. The shift to the second stage is characterized by a conscious increase in the sphere of creation and implementation of order and artificiality into the folk language environment. The less artificiality the language, the stronger the variable element of an oral speaking, not connected with any literary norms. In this case, the concept of "natural artificial" is revealed with the help of dichotomy of "oral - written".

In everyday communication, the process of creation and transformation of natural language by people occurs mostly automatically, in contrast to the professional domain, where the study and standardization of language are intentional and systemic. Literary language is a system of linguistic elements and means, selected from the national language and elaborated by word men, public figures, prominent scholars. In the scientific linguistic literature, the following main features of the literary language are determined: treatment, stability, obligingness, presence of oral and written forms, functional styles, and normalization. For native speakers, literary language is the highest form of national language. There is a constant interaction between the literary language and its nonliterary varieties. This is most clearly manifested in the spoken language. Thus, the peculiarities of speech of one or another dialect can characterize the spoken language of people who have a literary language. Thus, the concept of "natural - artificial" in the system of language is revealed using the dichotomy of "folk - literary".

The authors of a number of linguistic works offer descriptions of the natural language through the prism of the process of linguistic communication. Formulas of addressers and addressees are of great importance for linguistic researches. In this regard, the study of language etiquette is significant, since it is one of the indicators of interpersonal relations in the language. Language etiquette is one of the important elements of culture, an integral part of the overall system of human etiquette behaviour in a society. The dictionary of linguistic terms states that natural language is the "language in its own sense, human language as a natural tool of thought and means of communication, in contrast to its artificially created substitutes" (Akhmanova \& Mikaehlyan, 2003). In this context, the artificial language can be defined as a system of stable formulas of communication offered by society for establishing the contact of the interlocutors in accordance with their social roles in the official and informal environment, that is, in the form of etiquette.

We can distinguish common features of the language etiquette of virtually all peoples: the existence of stable formulas to attract the attention of the interlocutor, to show respect for him, to show sympathy, to create a comfortable climate for communication, etc. However, these features are 
realized in each culture in its own way. Typically, the most extended system of requirements exists in traditional cultures. Language etiquette remains an important part of the national language and culture, since each culture has its own century-old system of rules of linguistic communication and the ability to apply these rules in practice. With some convention, we can say that comprehension of language etiquette by its carriers has several stages. Making etiquette norms of behaviour in general and linguistic behaviour in particular obligatory for all individuals is typical for a closed traditional culture. The carrier of other language etiquette is perceived within this type of culture as a poorly educated person or as a negligent. The idea of the difference of language etiquette for different peoples, and the skills of imitation of other language behaviour can even be a subject of pride of members of societies open to external contacts.

In industrial and post-industrial cultures, the place of language etiquette is revised. Language etiquette is viewed in a purely pragmatic aspect as a means of achieving a communicative goal. The boundary between everyday linguistic practice and the norm in language etiquette is inevitably mobile. The practical use of language etiquette is always somewhat different from standard models, and not only because of insufficient knowledge of the participants of its rules. Language etiquette is related to the situation of linguistic communication and its parameters: personality of the interlocutor, subject, place, time, motive and purpose of communication. First of all, it is a complex of language phenomena, oriented to the addressee, whose identity is taken into account. The mentioned above allows asserting that the natural opposes artificial as "direct communication" opposes "etiquette-formed communication".

Humboldt (2000) expresses the idea that the language in its continuous change always maintains stability and at each given moment is a system with a regular correlation of its parts: 'The language is somewhat constant, while every moment is transient'. The viewpoint of Sossure (1999) sounds alike: 'At every moment, speech activity involves both the established system and evolution...'. Reflecting on this subject, F. de Sossure wrote: "The source of all changes is in speech; each of them, before entering into general use, begins to be used by a certain number of individuals' (Sossure, 1999).

In this context, it is reasonable to resort to the explanation of the "natural" as primary, objectively established, and artificial, in its turn, as secondary, generated by subjective will, interest, creativity.

Philosophical study of the subjective factor in the language has been going on for a long time. It should be noted that in linguistics, interest in this problem arose mainly due to the research of the founder of the philosophy of speech Humboldt (2000). The subjectivity of language, linguistic units is usually considered to be the information contained in the meaning of linguistic units, linguistic constructions, etc., and is opposed to their subject-logical (objective) content. In the sense of most linguistic elements, both of these types of information are present, but the quantitative ratio of objective and subjective information may be unequal.

The results of linguistic studies, in particular of Vezhbitskaya (1999), prove that the subjectlogical information, enclosed in the meaning of linguistic units, may include elements of subjectivity, which is usually associated with a specific, elaborated by a particular nation, attitude towards the world, a way of dealing with the objective reality. Thus, along with social and individual subjectivity, the national subjectivity is distinguished. If national subjectivity is a subjective component of the significance of the linguistic units inherent in one or another nation, social subjectivity is the subjective components of the meaning of linguistic units inherent in a particular social class, a social group, and the individual one is the subjective components of the linguistic units inherent in one or another man. Subjectively-valued components of the meaning dominate over the subject-logical in some elements of the language, while in others, on the contrary, subject-logical components are superior to subjective-valued ones.

The definition of the notion of subjectivity in the natural language requires attention to the possibility of the transition of the subjective into the objective and, conversely, the objective into the subjective. This possibility was intended by Humboldt (2000), introducing the pair of "objective - 
subjective" in his analysis of language antinomies, defined by him in the following way: "being relatively subjective in relation to cognitive, the language is objective in relation to a person.' And: 'the language belongs to me, because I reproduce it by my own activity; but because I reproduce it in this not other way, selected by all the generations that have passed it to each other till now, it is clear that I am limited by the language itself. But what limits me, giving a prominent direction to my activity, is due to the universal human nature that belongs to me on an equal basis with everyone, and therefore something strange in my language seems unfamiliar to me only at some point in my individual existence, but not in the main and the true essence of my nature' (Humboldt, 200o).

Undoubtedly, the emotionally-valued components of the meaning of linguistic units inherent in the nation will be objective for it. At the same time, for a nation speaking a different language, these components seem to be a subjectivity, in the same way as emotionally-valued components of the meaning of the linguistic units inherent in a particular class, a particular social group, will be an objectivity for them, while they will be a subjectivity for another class and group. In addition, according to the above mentioned antimony of objective and subjective in the language, at certain moments of the individuals existence the national and social, that is, objective in the language may become subjective for him, and his own individual definition of reality - objective and vice versa. In this case, the concept of "natural - artificial" is disclosed with the help of a paired construct of "objective - subjective".

Referring to the essence of the natural language, it should be taken into account that language is, first of all, a socio-cultural system (Salatino, 2018), that is, 'a semiotic system that coexists with culture in a single semantic space, interacting with the latter in a dialogue' (Bragina, 2013). The key to the existence of any linguistic layer is its use in social interaction, since the ontology of language systems is based on the causal mechanisms of the transfer of linguistic elements in a society in a communicative context (Enfield, 2014). Thus, according to Nalimov (2013), despite the discreteness and rigor, inherent in the language with the corresponding hierarchy inherent in it as a sign system, it is constantly in the process of development and updating, because the discreteness of the language is counterbalanced by the continuity of the deep consciousness. Thus, the language is sensitive to any changes associated with the emergence of new phenomena in society and culture, new technologies, including political and ideological ones, especially in periods of social and state instability. The language quickly responds to any changes and transforms itself. All changes in the life of society, even the slightest fluctuations in the structure of reality, cause an appropriate reaction in the language. As Lorenz (2016) observes, "human cultural development is ahead of its "nature", ideally the language "has" to try to keep up with the changes, giving the corresponding definitions to new phenomena'.

Culture always implies the dialectical unity of "old and new". In traditional cultures old is dominant, but modern culture transforms novelty into a value of almost absolute nature. The tendency to capturing the changes is often associated with the phenomenon of fashion in the linguistic-cultural field, which is characterized by catching up of socially objective tendencies of updating, subjective formation and stimulation of this updating, because, as modern philosophers note, 'the fashion in language exists in the same way as in clothes, footwear, perfumes' (Kostomarov \& Vereshchagin, 2014).

In the absence of the corresponding concept to indicate a new phenomenon in the cognitive basis of the language, the lack is filled not with the reliance on its own linguistic roots, but turns to be the result of donor-receptor relations between languages. Foreign borrowings are normal phenomena for the development of any language. Donor-receptor relations between languages can be rooted so much that even the relative closeness of a society is not a reliable protection against borrowings. There are different types of foreign borrowings: direct borrowings, hybrids, calques, semi-calques, terms, professionalisms, etc. It is interesting that periods of purism (from the Latin "purus" - pure) are observed in the development of any modern language, when all suddenly begin to "struggle" with foreign language vocabulary, replacing it with the vocabulary of the native language. The ratio of "natural - artificial" in this context is relevant to the categories of "native - borrowed".

Any natural language, no matter how widespread it is, is unable to become the universal 
language, since every language is a product of the mentality of a particular people. Hence, there are unsuccessful long-standing attempts to develop and spread a single language as a means of communication among different nationalities to replace the existing languages. The language designed for international communication is "artificial" by definition. The linguistic encyclopaedic dictionary gives the following definition: 'Artificial languages are sign systems that are created for use in those areas where the use of natural language is less effective or impossible' (Yartseva, 1990). Artificial languages are called to function in limited spheres, serving not the entire communicative community, but only a part of it. Thus, artificial languages are specially created in order to prevent third parties from understanding them (for example, jargon), or for communication between people engaged in certain professional matters (professional languages), or for the needs of those who have no opportunity to use a common language for some reason (for example, deaf or silent), or for trying to demonstrate the formal and structural capabilities of the language as such. Here, the ratio of "natural - artificial" is relevant to the categories of "tradition - innovation".

\subsection{Criteria for division into classes of natural and artificial languages}

As stated above, the "natural language" is one of the most important achievements of the social history of mankind, generated by different peoples and developed together with them. Artificial language, purposefully created by a person with certain characteristics and capabilities, is mostly presented in linguistic literature as a means of communication that does not belong to any people and does not contain any national culture. The era of the scientific and technological revolution has become a powerful incentive for building numerous communication systems focused on solving special tasks. At present, there are more than 1,500 varieties of artificial languages. Generally speaking, they all got the name according to the purpose of their creation and structure. However, this is not the basis for the terminological unity in the classification of artificial languages. In this work, we will use the classification of artificial languages proposed by Kuznetsov (n./d.):

\subsubsection{A priori languages}

A priori (logical or philosophical) languages are artificial languages, with the vocabulary and grammatical elements being not borrowed from natural languages, but created arbitrarily, or constructed on the basis of the logical (philosophical) concept.

The initial stage in constructing a priori languages is, for the most part, a pasigraphy - universal writing, which does not have an independent sound form. Acording to Leibniz (2015), characters in the pasigraphy must not only express ideas, but also create relationships (syntax) using ones similar to algebraic operations and replace ideas with formulas.

Nowadays, pasigraphies became part of "fantastic languages" as a creation of science fiction writers, authors of feature films and computer games. "Fantastic languages" were invented to serve the fantastic fictional worlds as the languages of peoples inhabiting them (for example, the fantastic world of Tolkien, the world of the Star Trek series, the world of the computer game Myst), in the face of the great popularity of some of these worlds, fantastic languages have gone beyond their limits and have become widespread in virtual reality, and sometimes in real life.

The idea of pasigraphy captivated European thinkers' minds almost to the second half of the $19^{\text {th }}$ century, when it became finally clear that the success of an artificial language was due to its proximity to the natural "phonetic verbal language", which one can use to speak and write. Nowadays, pasigraphies have become a part of "fantastic languages" - the creation of science fiction writers, authors of feature films and computer games.

Systems of a priori languages with the fixed form of expression: written (pazigraphy) or sign (pazimology), are opposed by the systems that seek endless variability of forms of expression (for example, the Solresol "musical language" founded by Sudre, which could be represented with sounds of music, numbers, gestures, colours of the spectrum, signals of a traffic light, etc.). 


\subsubsection{A posteriori languages}

A posteriori languages are in one or another way based on borrowings of lexical units and syntactic rules from natural languages. A posteriori languages are defined as a deliberately simplified version of the natural language or group of languages.

The most effective and popular a posteriori language in Europe is known to be the language created in 1887 by the Warsaw physician L. Zamenhof, whose nickname "Esperanto" gave the name to this artificial language. Esperanto is based on international vocabulary, mostly of Roman origin, but with German and Slavic elements. The grammar is simple and standardized (exceptions typical of "natural languages" are eliminated), the script is Latin-based, the word stress is on the penultimate syllable. Unlike other artificial constructions, Esperanto is "alive", since it is being modified, its vocabulary is increasing due to the considerable number of publications and activity of Associations of Esperantists.

\subsubsection{Mixed type of artificial languages}

The mixed type of artificial languages includes elements of natural languages, artificially created elements and links between them. A priori - a posteriori and a posterior - a priori languages are differentiated, depending on the predominance of a priori or a posteriori features, correspondingly. These systems differ from each other in the set of elements and their structuring, in their specific tasks and ways of functioning, the presence/absence of feedback, the degree of connection with the natural languages and other characteristics.

Examples of mixed languages can be programming languages and informational languages. Programming languages are complex in structure, but functionally they are close to natural. So, in addition to the representative function, they perform a communicative (serve as a means of representing (recording) of certain special information - a program that is given in the form of a sequence of individual commands to be performed by the user) and a cognitive function (acting as a means of symbolic representation of algorithms in the form of a sequence of complex actions). The development of programs with feedback allows man-machine-man communication, realizing the functions of situational evaluation, self-study and correction.

The typology of artificial languages given above, demonstrates that artificial and natural languages are opposed by a number of features, including:

1) origin and authorship;

2) functional areas of application;

3) richness and variety of elements.

Turning to the first criterion for the division of natural and artificial languages (the origin and authorship) one can find its unreliability. It is believed that the "natural" language occurs spontaneously, nobody creates it. On the contrary, an artificial language, being invented by somebody, later acts as a mediator in communication. Thus, there are no specific authors of the natural language, and at least one such creator is needed for an artificial one. Sometimes the name of an artificial language implies the name of its creator (for example, Morse Code). However, authors can be found in the case of natural languages too. It is, first of all, the introduction of linguistic norms, literary standards based on some dialects. An example is the modern German literary language. In fact, it is nothing but a posteriori auxiliary language.

Secondly, it is the reconstruction of ancient languages. It is not an exaggeration to say that such reconstruction usually has a clearer grammar than the observed languages, since the very procedure of comparative-historical reconstruction involves a phased elimination of illogicalities. An example is Hebrew. At the end of the $19^{\text {th }}$ century, when Ben-Yehuda began his work on the revival of Hebrew, which was the language of newspapers, magazines and books; it served as a language of communication for the Jews from different countries, but was completely excluded from everyday communication. This example demonstrates how a language that was not used in everyday life became alive and spoken again. 
Since natural language is an open system, that is, incomplete and fundamentally non-existent, it has a universal nature: 'Language, being the most important tool of communication of mankind, unites people, establishes their interpersonal and social relations, brings practical services in line, takes participation in the system of worldview and the idea of the national world, provides collection and preservation of information relating to history, the historical experience of the people, the personal experience of the individual, separates the concept of consciousness, groups and places, improves the mind and itself, serves as a form and material of artistic creativity' (Karaulov, 1997). This means that the natural language is used in all spheres of activity without exception, performing communicative (means of human communication), cognitive (means of cognition), emotional (means of expressing feelings and emotions), meta-linguistic (means of studying and describing the language in terms of the language itself), and other functions.

In view of the fact that artificial language can be created for real and/or fictitious people as a means of communication, one can conclude that an artificial language, as well as a natural one, performs a number of basic significant functions of the natural language, in particular, the ethnocreating one. The history of the mankind has examples where artificial language is intended to satisfy the social need for ethno-integration. Let's say, for a long time the Norwegians have been united by the Danish-Norwegian state language, so-called "Riksmal", or "Bokmal". But in the second half of the $19^{\text {th }}$ century in contrast to this foreign language, which became the language of the inhabitants of the cities and, at the same time, the language of literature, Osen I., using the elements of several peasant dialects, created a new language - Landsmal, that is, "rural". Landsmal's opponents rejected it as an artificial language, but it spread across the country, became as lively and literary as Bokmal, and was called "Nynorsk". In this way two national languages were formed in one nation. The third one has recently appeared, created on the basis of Bokmal and Nynorsk - "Samnorsk", which, according to the expectations of its creators and supporters, should become the only national language of the Norwegian people.

Despite the fact that natural and artificial languages are different in the nature of origin (the former occurs spontaneously, but not without the help of the people and has no authorship, and the latter is constructed by a man/people and, as a result, has at least one author), both of them are characterized as a system, as a single whole. An example is the Elven language family created by J.R. Tolkien. The author invented not only the alphabet for his languages, but also a dictionary, a series of phonetic, grammatical and syntactic rules that corresponds to the multilevel system of any natural language (Mitrofanov, 2018)

It is believed that unlike natural languages, formal ones can be described by the finite set of mechanized rules. However, among idiolects (individual variants of natural language) there are very simple languages. If the use of any of them is described as a set of such rules, will this idiolect, in its turn, be ranked among artificial languages? The idea of a categorical pair of "artificial - natural", which correspond to the characteristics of the language, are not reliable in the process of separating natural languages from artificial ones. From an activity point of view, artificial and natural are connected not with the characteristics of the language itself, but with different ways of its functioning (Shchedrovitsky, 2005).

\section{Conclusions}

The language as a holistic complex system is revealed as a result of the interaction of two mechanisms: artificial, regulated by goals, consciously used norms, expressed in teleological terms, and natural, shaped by spontaneous processes and authorized by traditions. A brief excursion into the history of linguistic studies proved the ratio of natural and artificial in the language is presented through the prism of a number of paired constructs: "natural - social", "oral - written"; "folk literary"; "informal - etiquette-formal"; "objective - subjective"; "autochthonous - borrowed"; "traditional - innovative". Natural and artificial languages are opposed on the basis of a number of features: origin and authorship; functional areas of application; reachness and variety of elements. 
However, the boundaries of the categories "natural" and "artificial" seem to be unclear. In this context, artificial and natural are associated with the attribution of artificial to the planned results usually in some selected areas with a set of elaborated elements, and natural, on the contrary, is relative to side effects of universal communicative-linguistic activities.

The degree of naturalization of language corresponds to the duration and scope of a communicative tradition, and the degree of artificiality is a linguistic innovation in the process of intentional language transformation.

\section{References}

Akhmanova, O. S., \& Mikaelyan, G. B. (2003). Modern syntactic theories. $\left(2^{\text {nd }}\right.$ ed.). Moscow: Editorial URSS.

Arbib, M. (2012). How the brain got language: The mirror system hypothesis. New York: Oxford University Press.

Aristotle. (2014). Physics. Moscow: KomKniga.

Baudouin de Courtenay, I. A. (2018). General Linguistics. Selected Works. Moscow: Yurait.

Bragina, N. G. (2013). Sociocultural constructs in the language: monograph. Moscow: Flint.

Corballis, M. C. (2017) The truth about language: what it is and where it came from. Chicago: University of Chicago Press.

Enfield, N. J. (2014). Natural causes of language: Frames, biases, and cultural transmission (Conceptual Foundations of Language Science 1). Berlin: Language Science Press.

Humboldt, V. (2000). About the different structure of languages and its influence on the spiritual development of the human race. Selected works on linguistics. Moscow: Progress.

Kamal, A. (2018). Human and Machine: Ethics of Conscious Artificial Intelligence. Humanities Commons. Available: https://hcommons.org/deposits/item/hc:21709/ (November 28, 2019)

Karaulov, Yu. N. (1997). Russian language. Encyclopedia. Moscow: Drofa.

Kirk, N. H, Nyga, D., \& Beetz, M. (2014). Controlled Natural Languages for Language Generation in Artificial Cognition. IEEE International Conference on Robotics and Automation (ICRA) (pp. 6667-6672). Hong Kong. doi: 10.1109/ICRA.2014.6907843

Kostomarov, V. G., \& Vereshchagin, E. N. (2014). Language and culture. Moscow: Direct Media.

Kutyrev, V. A. (1994). Natural and artificial: the struggle of worlds. Nizhny Novgorod.

Kuznetsov, S. N. (n./d.). On the typological classification of international artificial languages. The world of Esperanto. Available: http://miresperanto.com/esperantologio/tipologija.htm (November 28, 2019)

Leibniz, G. H. (2015). Logical Papers: A Selection Translated and Edited with an Introduction. Oxford: Oxford University Press.

Lorenz, K. (2016). Back side of the mirror. Nykoping: Philosophical arkiv.

Mitrofanov, G. A. (2018). Features of the creation of fictional languages in the literature of feces (based on the work ofJ. R. R. Tolkien). St. Petersburg: St. Petersburg. Polytechnic. University of Peter the Great.

Moskovsky, C., \& Libert, A. (2006). Questions in Natural and Artificial Languages. Journal of Universal Language, 7, 65-120. doi: 10.22425/jul.2006.7.2.65.

Nalimov, V. V. (2013). Probabilistic model of language. On the ratio of natural and artificial languages. Moscow: Book on demand.

Panov, E. N. (2017). Signs, Symbols, Languages: Communication in the Animal Kingdom and in the World of People. Moscow: URSS.

Salatino, D. R. (2018). Language Acquisition. International Journal of Research E Methodology in Social Science, 4(2), 1-14. doi: 10.5281/ZENODO.1322755.

Shchedrovitsky, G. P. (2005). Sign and activity: in 3 books. Book 2: Sign structure: meanings, meanings, knowledge. Moscow: Oriental literature.

Smokotin, V., Petrova, G., \& Gural, S. (2017). The role of natural languages as lingua francas in the course of human history. Language and Culture, 9, 58-69. doi: 10.17223/24109266/9/9.

Sossure, F. (1999). Course in General Linguistics. Ekaterinburg: Ural University.

Sova, L. Z. (2014). Fundamental laws of linguistics and artificial intelligence. Moscow; Berlin: Direct Media.

Tselishcheva, Z. A. (2016). Semiotic Component of Cultural and Communicative Space. International Research Journal. 8(50), Part 2, 30-82. doi: 10.18454/IRJ.2016.50.217.

Vezhbitskaya, A. (1999). Semantic universals and description of languages. Moscow: Languages of Russian culture.

Yartseva, V. N. (1990). Linguistic Encyclopedic Dictionary. Moscow: Soviet Encyclopedia. 